\title{
Adaptive Optimizing Control for Nonlinear Synchronous Generator System with Uncertain Disturbance
}

\author{
Guiyang Deng $\mathbb{D}^{1},{ }^{1}$ Lianglun Cheng $\mathbb{D}^{1},{ }^{1}$ and Baojian Yang $\mathbb{D}^{2}$ \\ ${ }^{1}$ School of Automation, Guangdong University of Technology, Guangzhou, Guangdong 510006, China \\ ${ }^{2}$ Faculty of Intelligent Manufacturing, Wuyi University, Jiangmen, Guangdong 529020, China \\ Correspondence should be addressed to Baojian Yang; kurt.yang@163.com
}

Received 19 June 2019; Revised 28 July 2019; Accepted 20 August 2019; Published 16 October 2019

Copyright (C) 2019 Guiyang Deng et al. This is an open access article distributed under the Creative Commons Attribution License, which permits unrestricted use, distribution, and reproduction in any medium, provided the original work is properly cited.

\begin{abstract}
In this paper, an adaptive optimizing control is proposed for nonlinear synchronous generator system with uncertain disturbance. Considering the issue of uncertain item, a low-order Extended State Observer (ESO) is constructed to track each order states. Then, combining Backstepping technology and proposed ESO, a dynamic compensation control is designed to compensate the uncertainty disturbance in each state quantity. The proposed method demonstrated that stability of the system can be ensured, and tracking burden of ESO can be reduced. Finally, simulation results can show a good tracking performance and anti-interference ability by the proposed control method.
\end{abstract}

\section{Introduction}

At present, the energy development in the world is mostly hydraulic power generation, thermal power generation, wind power generation and so on. In modern power industry, synchronous generator is the most commonly used alternator, which is widely used in thermal power generation, diesel engine power generation, nuclear power generation, and so on [1-3]. During the operation of synchronous generators, there are many system uncertainties and serious external disturbances. It would lead to great energy loss and bring great negative impact on energy conversion efficiency. Therefore, how to effectively compensate for uncertain nonlinearity and improve energy conversion efficiency is an open issue. To achieve high-performance power system control, it is necessary to overcome the negative effects of uncertainties and nonlinear factors in the system. For the complex synchronous generator model, it is feasible to analyze the stability of synchronous generator directly by using Lyapunov function, but the calculation process is complex and the amount of calculation is large [4-6]. There are many uncertain disturbances in the actual application scenario of synchronous generator, which makes the design of control method greatly difficult.

Since there are many uncertainties and unknown disturbances during the operation of the synchronous generator, it is very difficult to construct the Lyapunov function directly. At present, some scholars use Backstepping technology to construct Lyapunov functions effectively. They have completed the design of the whole system control law [7-9]. Although Backstepping technology effectively reduces the difficulty of constructing Lyapunov functions, it is still difficult to construct systems with multiple uncertainties. In this regard, some scholars use adaptive control based on the Backstepping technology to compensate for uncertainty interference [10-15]. However, this method increases the number of adaptive parameters, so that the amount of calculation increases.

On the other hand, for systems with uncertainties, Extended State Observer (ESO) is used to achieve effective dynamic tracking [16-20]. The ESO is used to expand the uncertain disturbances in the system into a new state. By adopting ESO, the uncertain disturbances can be tracked efficiently. Moreover, the control accuracy of the system can be improved by using the tracking values of uncertain disturbances. However, the ESO designed for the whole system model will accumulate disturbances as the dimension of the system model increases. This will result in the performance of the observer greatly reduced. Furthermore, in practical application scenarios, synchronous generators are structure complex system. And uncertain disturbances are uncertain. In 
order to broaden the application scenario of ESO, it is necessary to optimize the construction method of ESO.

To sum up, this paper designs a controller based on Backstepping technology and low-order ESO to enhance the anti-interference ability of the system and improve the efficiency of energy conversion. The specific mathematical model of this paper is described in Section 2. The proposed control method is described in detail in Section 3. The corresponding simulation is shown in Section 4.

\section{Mathematical Model of Synchronous Generator}

In this paper, a mathematical model of synchronous generator based on rotor $d-q$ axis is considered. And $L=L_{q}=L_{d}$ is one of the assumptions.

$$
\left\{\begin{array}{l}
\dot{\theta}=\omega \\
\dot{\omega}=\frac{1}{J}\left(\frac{3 p \phi_{f}}{2} i_{q}-B \omega\right)-d \\
\dot{i}_{d}=\frac{1}{L} u_{d}+p \omega i_{q}-\frac{R}{L} i_{d} \\
\dot{i}_{q}=\frac{1}{L} u_{q}-\frac{p \phi_{f}}{L} \omega-\frac{R}{L} i_{q}-p \omega i_{d}+f
\end{array}\right.
$$

where $\theta$ is the rotor angle, $B$ is the viscous friction coefficient, $p$ is the pole logarithm, and $J$ is the moment of inertia of the rotor. $R$ and $L$ are the stator resistance and phase inductance, respectively. $\omega$ the mechanical angular velocity. $i_{d}$ and $i_{q}$ are current of $d-q$ axis. $\phi_{f}$ is the permanent magnet flux. $u_{d}$ and $u_{q}$ are voltage of $d-q$ axis. $d$ represents the unknown load torque disturbances. $f$ is the externally uncertain bounded disturbances term.

In the magnetic field control of a synchronous generator, the direct current $i_{d}$ is generally set to zero. Therefore, the model (1) of the synchronous generator can be simplified as follows:

$$
\left\{\begin{array}{l}
\dot{\theta}=\omega, \\
\dot{\omega}=-c_{1} \omega+c_{2} i_{q}-d, \\
\dot{i}_{q}=-c_{3} \omega-c_{4} i_{q}+b u_{q}+f,
\end{array}\right.
$$

where $c_{1}=B / J, c_{2}=k_{T} / J, c_{3}=p \phi_{f} / L, c_{4}=R / L, b=1 / L$, and $k_{T}=3 p \phi_{f} / 2$.

In order to facilitate the design of the controller, $x_{1}=\theta$, $x_{2}=\omega$, and $x_{3}=i_{q}$ are the system status. Thus, the model (2) can be described as follows:

$$
\left\{\begin{array}{l}
\dot{x}_{1}=x_{2}, \\
\dot{x}_{2}=-c_{1} x_{2}+c_{2} x_{3}-d, \\
\dot{x}_{3}=-c_{3} x_{2}-c_{4} x_{3}+b u_{q}+f .
\end{array}\right.
$$

Setting

$$
u_{q}=\frac{h+c_{3} x_{2}+c_{4} x_{3}}{b},
$$

where $h$ is the preset control amount.

Then formula (3) is further represented as follows:

$$
\left\{\begin{array}{l}
\dot{x}_{1}=x_{2}, \\
\dot{x}_{2}=-c_{1} x_{2}+c_{2} x_{3}-d, \\
\dot{x}_{3}=h+f .
\end{array}\right.
$$

The system model (5) is a system with uncertain disturbance terms. Based on the Backstepping technology, this paper combines the ESO method to design a control method. It improves the anti-interference ability of the system and further ensures the stability and tracking performance of the system. The design method is described in the next section.

\section{Compensation Control Design}

According to the aforementioned model, the design steps of the control method are as follows.

Step 1. Define tracking error $e_{1}$ as follows:

$$
e_{1}=x_{1}-x_{1 r}
$$

where $x_{1 r}$ is the expected value, and the second order is derivable.

The Lyapunov function is defined as follows:

$$
V_{1}=\frac{1}{2} e_{1}^{2}
$$

Thus, it can be obtained as follows:

$$
\dot{V}_{1}=e_{1} \dot{e}_{1}=e_{1}\left(x_{2}-\dot{x}_{1 r}\right) \text {. }
$$

Define the tracking error $e_{2}$ as follows:

$$
e_{2}=x_{2}-\alpha_{1}
$$

where $\alpha_{1}$ is the virtual controller.

From formulas (8) and (9), it can be obtained as follows:

$$
\dot{V}_{1}=e_{1}\left(e_{2}+\alpha_{1}-\dot{x}_{1 r}\right) \text {. }
$$

To ensure that $\dot{V}_{1}$ is negative, the virtual controller is designed as $\alpha_{1}=-k_{1} e_{1}+\dot{x}_{1 p}$, where $k_{1}>0$. Then, the following result can be obtained:

$$
\dot{V}_{1}=-k_{1} e_{1}^{2}+e_{1} e_{2} .
$$

In the above formula, the inequality $-k_{1} e_{1}^{2} \leq 0$ is always established. The processing of the item $e_{1} e_{2}$ is described in the next step.

Step 2. The Lyapunov function $V_{2}$ is chosen as:

$$
V_{2}=V_{1}+\frac{1}{2} e_{2}^{2}
$$

Thus, it can be obtained that:

$$
\dot{V}_{2}=-k_{1} e_{1}^{2}+e_{2}\left(e_{1}-c_{1} x_{2}+c_{2} x_{3}-d-\dot{\alpha}_{1}\right) .
$$

Define tracking error $e_{3}$ as follows:

$$
e_{3}=x_{3}-\alpha_{2} \text {. }
$$

Thus, the system status is described as follows:

$$
x_{3}=e_{3}+\alpha_{2} .
$$

From formulas (13) and (15), it can be obtained as follows:

$$
\dot{V}_{2}=-k_{1} e_{1}^{2}+e_{2}\left[e_{1}-c_{1} x_{2}+c_{2}\left(e_{3}+\alpha_{2}\right)-d-\dot{\alpha}_{1}\right] \text {. }
$$


In order to satisfy the inequality $\dot{V}_{2} \leq 0$, the virtual controller $\alpha_{2}$ is designed as follows:

$$
\alpha_{2}=\frac{1}{c_{2}} \dot{\alpha}_{1}+\frac{c_{1}}{c_{2}} x_{2}+\frac{1}{c_{2}} d-\frac{1}{c_{2}} e_{1}-\frac{k_{2}}{c_{2}} e_{2} .
$$

Then, it can be obtained the following formula:

$$
\dot{V}_{2}=-k_{1} e_{1}^{2}-k_{2} e_{2}^{2}+c_{2} e_{2} e_{3},
$$

where $k_{1}>0$ and $k_{2}>0$. Therefore, $-k_{1} e_{1}^{2}-k_{2} e_{2}^{2} \leq 0$ is established. Then, further design is needed to eliminate the impact of the error $e_{3}$ on system stability.

Formula (16) contains an externally bounded disturbance $d$. In order to ensure the stability of the system, the second-order ESO-1 is constructed to estimate the external uncertain, which is bounded interference. The construction method will be introduced in the subsection.

The ESO-1 is established as follows:

$$
\left\{\begin{array}{l}
e_{d 1}=z_{d 1}-x_{2}, \\
\dot{z}_{d 1}=z_{d 2}-\beta_{d 1} e_{d 1}-c_{1} x_{2}+c_{2} x_{3}, \\
\dot{z}_{d 2}=-\beta_{d 2} f a l\left(e_{d 1}, \varepsilon_{d}, \delta_{d}\right) .
\end{array}\right.
$$

The function $f a l\left(e_{d 1}, \varepsilon_{d}, \delta_{d}\right)$ is designed as follows:

$$
f a l\left(e_{d 1}, \varepsilon_{d}, \delta_{d}\right)= \begin{cases}\frac{e_{d 1}}{\delta_{d}^{\varepsilon_{d}-1}}, & \left|e_{d 1}\right| \leq \delta_{d}, \\ \left|e_{d 1}\right|^{\varepsilon_{d}} \operatorname{sign}\left(e_{d 1}\right), & \left|e_{d 1}\right|<\delta_{d},\end{cases}
$$

where $e_{d 1}$ is the systematic error, $\varepsilon_{d}$ is a constant in the interval $(0,1)$. And $\delta_{d}$ is the length of the interval of the linear segment.

The stability of the second order ESO-1 of formula (19) is demonstrated as follows:

Setting

$$
\left\{\begin{array}{l}
e_{d 1}=z_{d 1}-x_{2} \\
e_{d 2}=z_{d 2}-d
\end{array}\right.
$$

Thus, it can be obtained as follows:

$$
\left\{\begin{array}{l}
\dot{e}_{d 1}=e_{d 2}-\beta_{d 1} e_{d 1}, \\
\dot{e}_{d 2}=-\beta_{d 2} f a l\left(e_{d 1}, \varepsilon_{d}, \delta_{d}\right)-\dot{d}
\end{array}\right.
$$

Case 1. The error $\mathrm{e}_{d 1}$ is satisfied with $\left|e_{d 1}\right|>\varepsilon_{d}$, and then it can be obtained that $\operatorname{fal}\left(e_{d 1}, \varepsilon_{\mathrm{d}}, \delta_{d}\right)=\left|e_{d 1}\right|^{\varepsilon_{d}} \operatorname{sign}\left(e_{d 1}\right)$.

$$
\left\{\begin{array}{l}
\dot{e}_{d 1}=e_{d 2}-\beta_{d 1} e_{d 1}, \\
\dot{e}_{d 2}=\mp \beta_{d 2}\left|e_{d 1}\right|^{\varepsilon_{d}}-\dot{d} .
\end{array}\right.
$$

When the system is stable, it can be obtained that $\dot{e}_{d 1} \rightarrow 0$ and $\dot{e}_{d 2} \rightarrow 0$

$$
\left\{\begin{array}{l}
\dot{e}_{d 1}=e_{d 2}-\beta_{d 1} e_{d 1}=0 \\
\dot{e}_{d 2}=\mp \beta_{d 2}\left|e_{d 1}\right|^{\varepsilon_{d}}-\dot{d}=0,
\end{array}\right.
$$

and

$$
\left\{\begin{array}{l}
e_{d 1}=\mp\left|\frac{\dot{d}}{\beta_{d 2}}\right|^{\varepsilon_{d}^{-1}}, \\
e_{d 2}= \pm \beta_{d 1}\left|\frac{\dot{d}}{\beta_{d 2}}\right|^{\varepsilon_{d}^{-1}} .
\end{array}\right.
$$

Therefore, if the inequality $\left|\beta_{d 2}\right|>|\dot{d}|$ was established with the true parameters, it could be obtained $z_{d 1} \rightarrow x_{2}, z_{d 2} \rightarrow d$.

Case 2. The error $\mathrm{e}_{d 1}$ is satisfied by $\left|e_{d 1}\right| \leq \varepsilon_{d}$, it can be obtained $\operatorname{fal}\left(e_{d 1}, \varepsilon_{\mathrm{d}}, \delta_{d}\right)=e_{d 1} / \delta_{d}^{\varepsilon_{d}-1}$.
Then,

$$
\left\{\begin{array}{l}
\dot{e}_{d 1}=e_{d 2}-\beta_{d 1} e_{d 1} \\
\dot{e}_{d 2}=-\beta_{d 2} \frac{e_{d}^{\varepsilon_{d}-1}}{\delta_{d}^{\varepsilon_{d}}} \dot{d}
\end{array}\right.
$$

When the system is stable, it can be obtained that $\dot{e}_{d 1} \rightarrow 0$ and $\dot{e}_{d 2} \rightarrow 0$. Thus

$$
\left\{\begin{array}{l}
\dot{e}_{d 1}=e_{d 2}-\beta_{d 1} e_{d 1}=0 \\
\dot{e}_{d 2}=-\beta_{d 2} \frac{e_{d}}{\delta_{d}^{\varepsilon_{d}-1}}-\dot{d}=0
\end{array}\right.
$$

and

$$
\left\{\begin{array}{l}
e_{d 1}=-\frac{\dot{d} \cdot \delta_{d}^{\varepsilon_{d}-1}}{\beta_{d 2}} \\
e_{d 2}=-\beta_{d 1} \frac{\dot{d} \cdot \delta_{d}^{\varepsilon_{d}}-1}{\beta_{d 2}}
\end{array}\right.
$$

Similarly, if the inequality $\left|\beta_{d 2}\right|>\left|\dot{d} \cdot \delta_{d}^{\varepsilon_{d}-1}\right|$ was established with the true parameters, it could be obtained $z_{d 1} \rightarrow x_{2}$ and $z_{d 2} \rightarrow d$.

From case 1 and case 2, the stability of the second-order ESO-1 can be ensured when the appropriate parameters are satisfied with $\left|\beta_{d 2}\right|>|\dot{d}|$ and $\left|\beta_{d 2}\right|>\left|\dot{d} \cdot \delta_{d}^{\varepsilon_{d}-1}\right|$.

Step 3. The Lyapunov function $V_{3}$ is chosen as:

$$
V_{3}=V_{2}+\frac{1}{2} e_{3}^{2}
$$

Thus, it can be obtained that:

$$
\dot{V}_{3}=-k_{1} e_{1}^{2}-k_{2} e_{2}^{2}+c_{2} e_{2} e_{3}+e_{3} \dot{e}_{3} .
$$

From formula (14), it can be obtained that $\dot{e}_{3}=\dot{x}_{3}-\dot{\alpha}_{2}$. Thus, $\dot{V}_{3}$ can be written as:

$$
\dot{V}_{3}=-k_{1} e_{1}^{2}-k_{2} e_{2}^{2}+c_{2} e_{2} e_{3}+e_{3}\left(h+f-\dot{\alpha}_{2}\right) .
$$

In order to satisfy the inequality $\dot{V}_{2} \leq 0$, it can be designed as follows:

$$
h=-f+\dot{\alpha}_{2}-k_{3} e_{3}-c_{2} e_{2},
$$

where $k_{3}>0$. Formula (30) contains an externally bounded disturbance $f$. Similarly, the second-order ESO-2 is designed to estimate the uncertainty disturbance.

Thus, the ESO-2 is established as follows:

$$
\left\{\begin{array}{l}
e_{f 1}=z_{f 1}-x_{3}, \\
\dot{z}_{f 1}=z_{f 2}-\beta_{f 1} e_{f 1}-c_{3} x_{2}-c_{4} x_{3}+b u_{q}, \\
\dot{z}_{f 2}=-\beta_{f 2} \operatorname{fal}\left(e_{f 1}, \varepsilon_{f}, \delta_{f}\right) .
\end{array}\right.
$$

The function $\operatorname{fal}\left(e_{f 1}, \varepsilon_{f}, \delta_{f}\right)$ is designed as follows:

$$
f a l\left(e_{f 1}, \varepsilon_{f}, \delta_{f}\right)= \begin{cases}\frac{e_{f 1}}{\delta_{f}-1}, & \left|e_{f 1}\right| \leq \delta_{f}, \\ \left|e_{f 1}\right|^{\varepsilon_{f}} \operatorname{sign}\left(e_{f 1}\right), & \left|e_{f 1}\right|<\delta_{f},\end{cases}
$$

where $e_{f 1}$ is the systematic error, $\varepsilon_{f}$ is a constant in the interval $(0,1)$, and $\delta_{f}$ is the length of the interval of the linear segment. 
TABLE 1: Parameters of synchronous generator.

\begin{tabular}{lc}
\hline Parameters & Ratings \\
\hline Torque constant $k_{T}$ & $0.14 \mathrm{~N} \cdot \mathrm{m} \cdot \mathrm{A}^{-1}$ \\
Number of pole pairs $p$ & 4 \\
Stator phase resistance $R$ & $2 \Omega$ \\
Stator phase inductance $L$ & $25 \mathrm{mH}$ \\
Coefficient of friction $B$ & $0.0001 \mathrm{~N} \cdot \mathrm{m} \cdot \mathrm{s} \cdot \mathrm{rad}^{-1}$ \\
Moment of inertia $J$ & $0.0086 \mathrm{~kg} \cdot \mathrm{m}^{2}$ \\
\hline
\end{tabular}

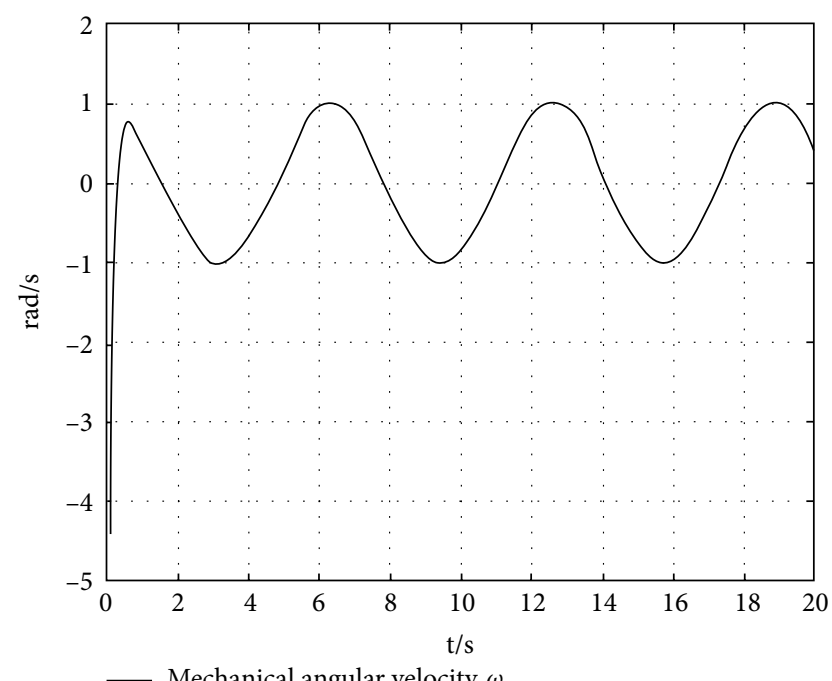

— Mechanical angular velocity $\omega$

FIgURE 1: Mechanical angular velocity $\omega$.

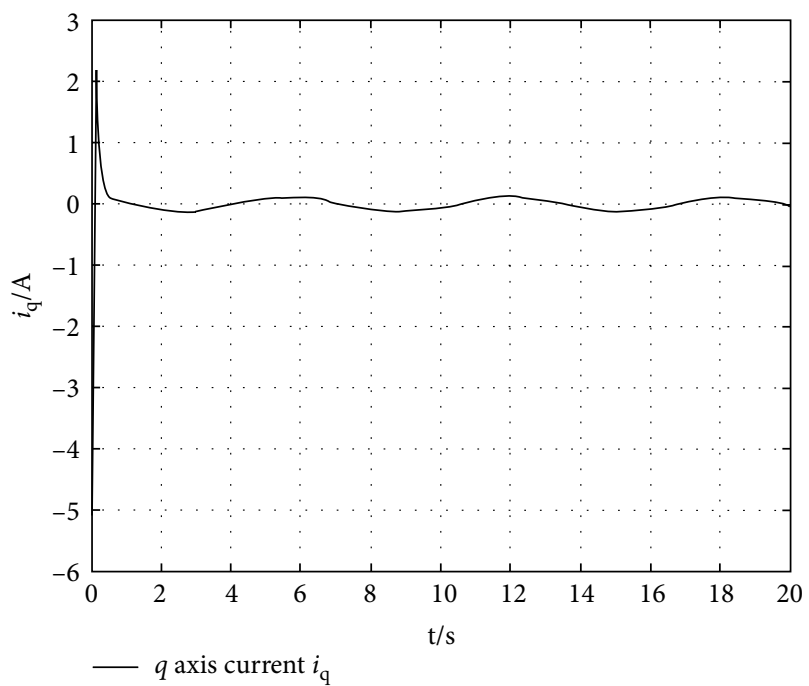

FIGURE 2: $q$ axis current $i_{q}$.

Same as ESO-1 stability proof process, the stability of ESO-2 can be guaranteed when both $\left|\beta_{f 2}\right|>|\dot{f}|$ and $\left|\beta_{f 2}\right|>\left|\dot{f} \cdot \delta_{f}^{\varepsilon_{f}-1}\right|$ are satisfied.

According to the aforementioned analysis, ESO-2 can accurately estimate the uncertainty disturbance $f$ in real time. Therefore, formula (30) can be rewritten as:

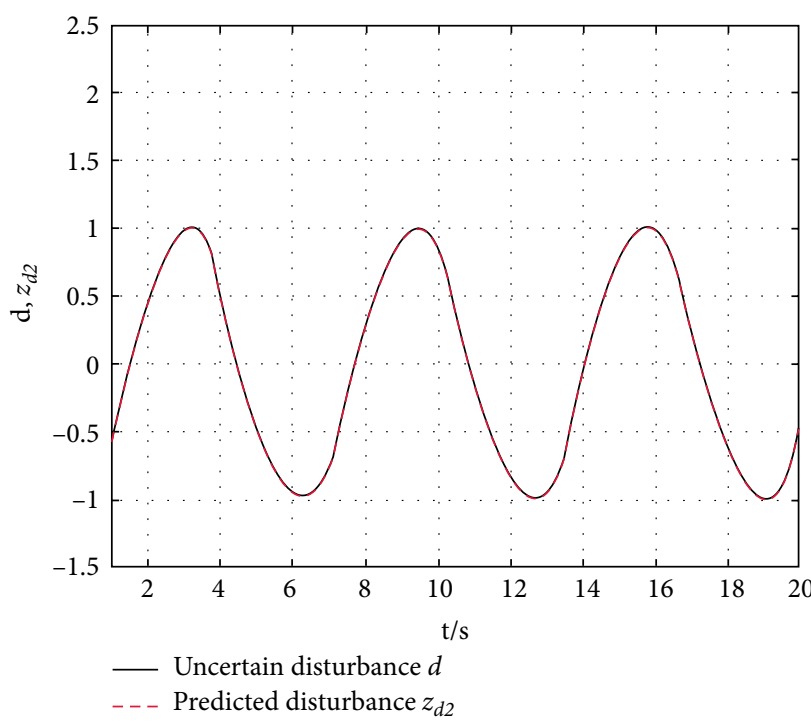

FIGURE 3: Uncertain disturbance $d$ and predicted disturbance $z_{d 2}$.

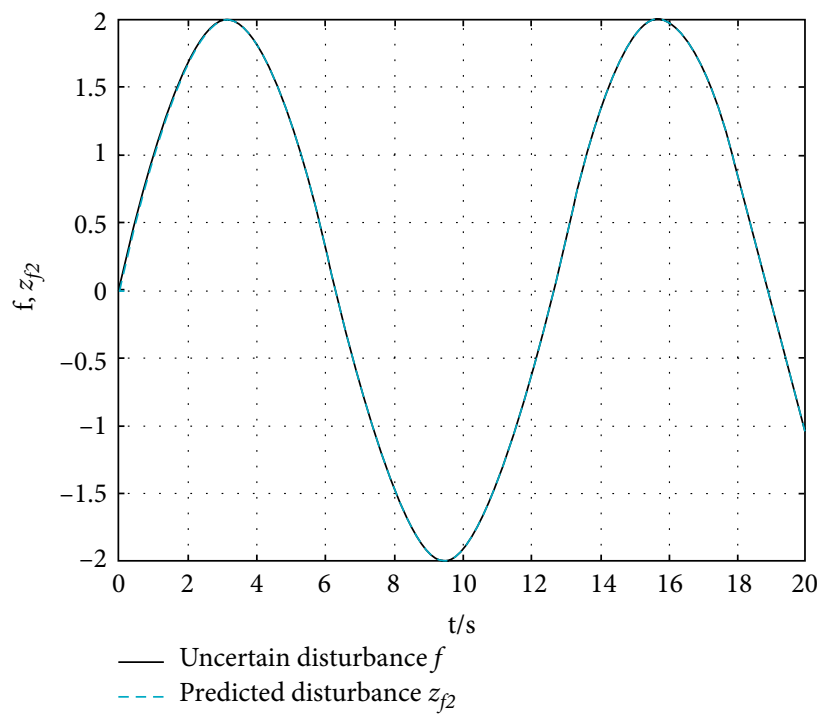

FIGURE 4: Uncertain disturbance $f$ and predicted disturbance $z_{f 2}$.

$$
\dot{V}_{3}=-k_{1} e_{1}^{2}-k_{2} e_{2}^{2}-k_{3} e_{3}^{2} \leq 0 .
$$

In summary, the system model (1) is stablity.

\section{Simulation Results}

In order to verify the feasibility of the above method, the following verification simulation is performed for the synchronous generator control system model. The parameters are shown in Table 1.

The parameters of the system model are derived from the data in Table 1. And choosing $c_{1}=0.5, c_{2}=16.28, c_{3}=26$, $c_{4}=80$, and $b=40$. In the simulation, the initial value of the equation of state is set as $\left[\begin{array}{lll}x_{1}(0) & x_{2}(0) & x_{3}(0)\end{array}\right]=\left[\begin{array}{lll}1 & 0 & 0\end{array}\right]$. The parameters in the Backstepping technology are selected 

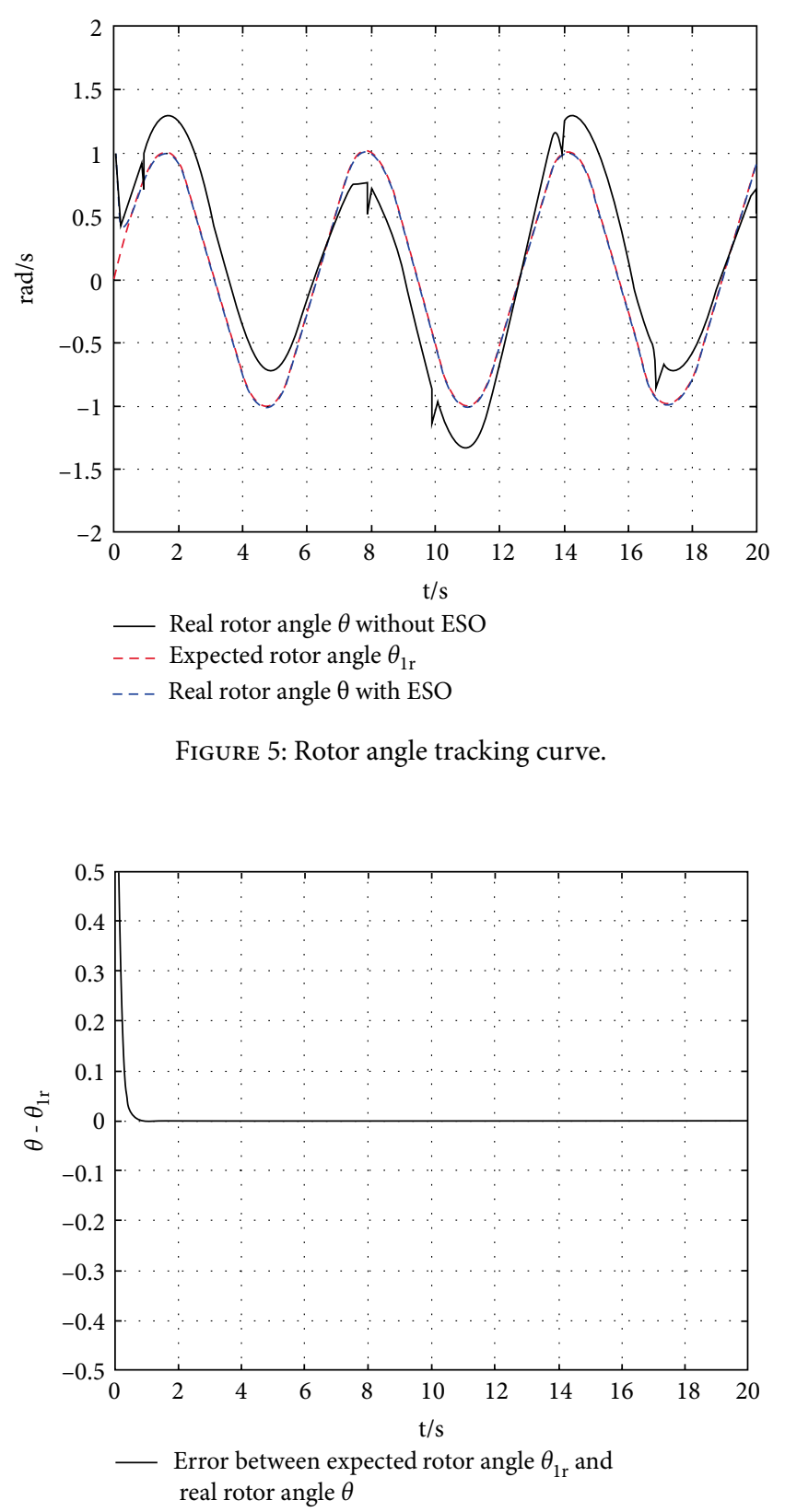

FIGURE 6: Error between expected rotor angle $\theta_{1 r}$ and real rotor angle $\theta$.

as: $k_{1}=30, k_{2}=40$, and $k_{3}=0.1$. The parameters in ESO are selected as: $\beta_{d 1}=\beta_{f 1}=100, \beta_{f 1}=\beta_{f 2}=100, \varepsilon_{d}=\varepsilon_{f}=0.5$, and $\delta_{d}=\delta_{f}=0.01$.

In order to track the rotor angle and verify the stability of the system, the expected value of the given rotor angle in the simulation example is $\theta_{1 r}=x_{1 r}=\sin (t) \mathrm{rad} / \mathrm{s}$. And assume that the system's uncertain disturbance terms are $d=\cos (t)$ and $f=2 * \sin (t / 2)$. The simulation results are shown in Figures 1-6.

It can be seen from Figures 1 and 2 that both the mechanical angular velocity and the $q$-axis current are bounded, which guarantees the stability of the system. It can be seen from Figures 3 and 4 that the established ESO can perform effective dynamic compensation for the uncertain interference term and good real-time tracking. Figure 5 is a comparison of the real rotor angle control with ESO and without ESO. The figure indicates that the system without ESO will more easily affect by the uncertain disturbances and generate the system jitter. This must not be allowed to exist in the practical engineering application. By using the proposed method, the system has stronger anti-interference ability and satisfies the practical engineering requirements. Figure 6 is the error between the two. The error curve is basically stable at 0 , that is, the error is close to zero. It can be seen that the method proposed in this paper can improve the stability of the system and has great practical application value.

\section{Conclusions}

Based on the model of synchronous generator system, this paper proposes a new control method by combining Backstepping design method and ESO method. Firstly, a low-order ESO is constructed, which can estimate the uncertain disturbances in real-time. Secondly, the Lyapunov function of the synchronous generator system model is constructed effectively by using Backstepping method. On the premise of reducing the amount of calculation, a control method is designed to achieve effective tracking and strong antijamming performance of the system. The simulation results show that this method can improve the antijamming ability and tracking performance of the system, and has great application value.

\section{Data Availability}

The paper data used to support the findings of this study are included within the article.

\section{Conflicts of Interest}

The authors declare that there are no conflicts of interest regarding the publication of this paper.

\section{Acknowledgments}

This work has been supported by the National Natural Science Foundation of China Guangdong Joint Funds (Grant No. U1701262 and No. U1801263) and partly supported by the Guangdong Provincial Key Laboratory of Cyber-Physical System (Grant No. 2016B030301008) and the Guangdong applied science and technology R \& D special funds (Grant No. 2015B090922013) and the Guangdong Province Science and Technology Project (Grant No. 2016B090918017) and the Guangdong NC First Generation Project (Grant No. 2013B011302007) and the Guangzhou Science and Technology Project (Grant No. 201604016107) and funding for Introduced Innovative R\&D Team Program of Jiangmen (Grant No. 2018630100090019844) and Youth Scientific Research Fund Project of Wuyi University (2015ZK06). 


\section{References}

[1] V. Natarajan and G. Weiss, "Almost global asymptotic stability of a grid-connected synchronous generator," Mathematics of Control, Signals, and Systems, vol. 30, no. 2, pp. 10, 2018.

[2] K. Sindhya, A. Manninen, K. Miettinen, and J. Pippuri, "Design of a permanent magnet synchronous generator using interactive multiobjective optimization," IEEE Transactions on Industrial Electronics, vol. 64, no. 12, pp. 9776-9783, 2017.

[3] X. Bai, L. Qu, and W. Qiao, "Robust AC optimal power flow for power networks with wind power generation," IEEE Transactions on Power Systems, vol. 31, no. 5, pp. 4163-4164, 2015.

[4] T. de Paula Machado Bazzo, J. F. Kolzer, R. Carlson, F. Wurtz, and L. Gerbaud, "Multiphysics design optimization of a permanent magnet synchronous generator," IEEE Transactions on Industrial Electronics, vol. 64, no. 12, pp. 9815-9823, 2018.

[5] T. Barisa, S. Iles, D. Sumina, and J. Matusko, "Model predictive direct current control of a permanent magnet synchronous generator based on flexible Lyapunov function considering converter dead time," IEEE Transactions on Industry Applications, vol. 54, no. 3, pp. 2899-2912, 2018.

[6] J. Wang, Z. Liu, Y. Zhang, C. L. P. Chen, and G. Lai, "Adaptive neural control of a class of stochastic nonlinear uncertain systems with guaranteed transient performance," IEEE Transactions on Cybernetics, pp. 1-11, 2019.

[7] X. Bai and W. Qiao, "Robust optimization for bidirectional dispatch coordination of large-scale V2G," IEEE Transactions on Smart Gird, vol. 6, no. 4, pp. 1944-1954, 2015.

[8] F. Mazenc and H. Ito, "Lyapunov technique and backstepping for nonlinear neutral systems," IEEE Transactions on Automatic Control, vol. 58, no. 2, pp. 512-517, 2013.

[9] X. Bai, W. Qiao, H. Wei, F. Huang, and Y. Chen, "Bidirectional coordinating dispatch of large-scale V2G in a future smart grid using complementarity optimization," International Journal of Electrical Power \& Energy Systems, vol. 68, pp. 269-277, 2015.

[10] J. Wang, Z. Liu, Y. Zhang, and C. L. P. Chen, "Neural adaptive event-triggered control for nonlinear uncertain stochastic systems with unknown hysteresis," IEEE Transactions on Neural Networks and Learning Systems, pp. 1-13, 2019.

[11] G. Wen, S. S. Ge, and F. Tu, "Optimized backstepping for tracking control of strict-feedback systems," IEEE Transactions on Neural Networks and Learning Systems, vol. 29, no. 8, pp. 3850-3862, 2018.

[12] D. Sheng, Y. Wei, S. Cheng, and J. Shuai, "Adaptive backstepping control for fractional order systems with input saturation," Journal of the Franklin Institute, vol. 354, no. 5, pp. 2245-2268, 2017.

[13] C. Wei, M. Benosman, and T. Kim, "Online parameter identification for state of power prediction of lithiumion batteries in electric vehicles using extremum seeking," International Journal of Control, Automation and System, 2019.

[14] K. Miroslav, K. Ioannis, and V. Petar, Nonlinear and Adaptive Control Design, Englewood Cliffs, NJ, 1994.

[15] J. Wang, H. Zhu, C. L. Zhang et al., "Adaptive hyperbolic tangent sliding-mode control for building structural vibration systems for uncertain earthquakes," IEEE Access, vol. 6, pp. 7472874736, 2018.

[16] S. Wang, X. Ren, J. Na, and T. Zeng, "Extended-state-observerbased funnel control for nonlinear servomechanisms with prescribed tracking performance," IEEE Transactions on Automation Science and Engineering, vol. 14, no. 1, pp. 98-108, 2016.

[17] C. Wei, Z. Zhang, W. Qiao, and L. Qu, "An adaptive networkbased reinforcement learning method for MPPT control of PMSG wind energy conversion systems," IEEE Transactions on Power Electronics, vol. 31, no. 11, pp. 7837-7848, 2016.

[18] X. Wang, C. Shi, and S. Wang, "Extended state observer-based motion synchronization control for hybrid actuation system of large civil aircraft," International Journal of Systems Science, vol. 48, no. 10, pp. 2212-2222, 2017.

[19] J. Wang, W. Chen, Z. Chen et al., "Neural terminal sliding-mode control for uncertain systems with building structure vibration," Complexity, vol. 2019, Article ID 1507051, 9 pages, 2019.

[20] C. Wei, Z. Zhang, W. Qiao, and L. Qu, "Reinforcement-learningbased intelligent maximum power point tracking control for wind energy conversion systems," IEEE Transactions on Industrial Electronics, vol. 62, no. 10, pp. 6360-6370, 2015. 


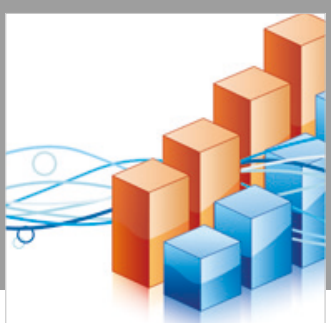

Advances in

Operations Research

\section{-n-m}
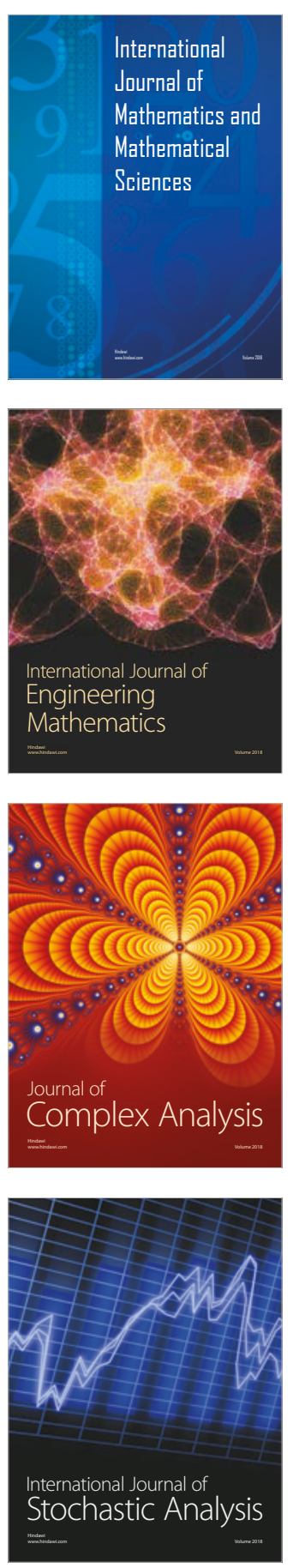
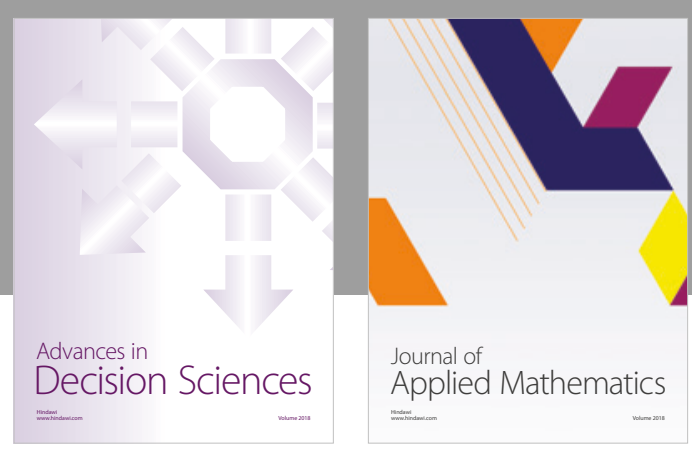

Journal of

Applied Mathematics
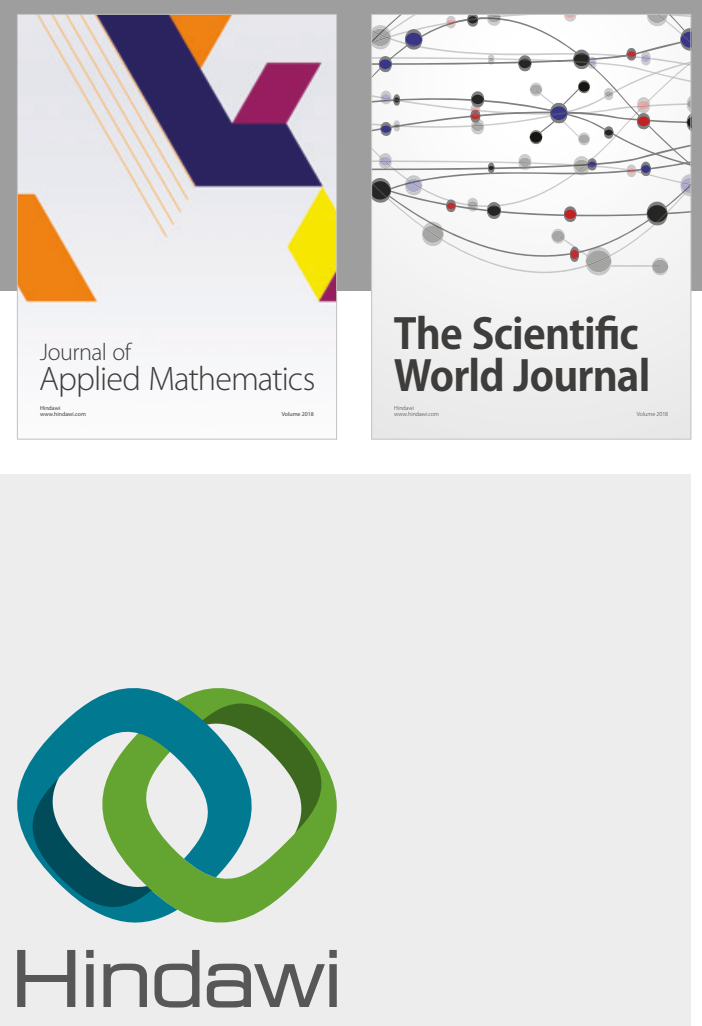

Submit your manuscripts at

www.hindawi.com

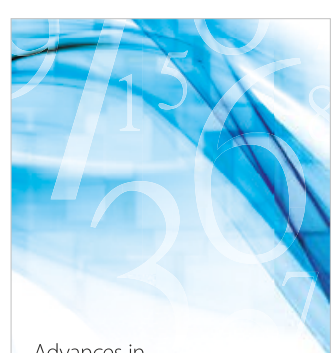

Advances in
Numerical Analysis
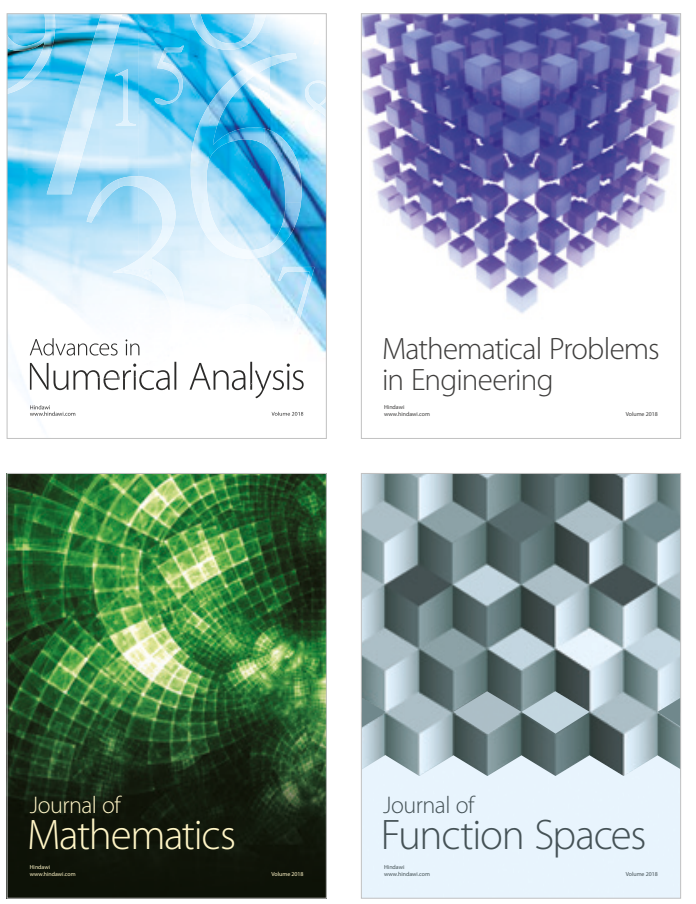

Mathematical Problems in Engineering

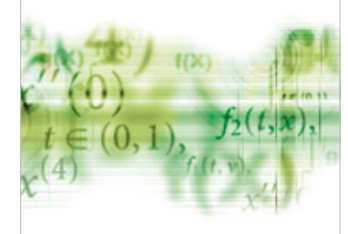

International Journal of

Differential Equations

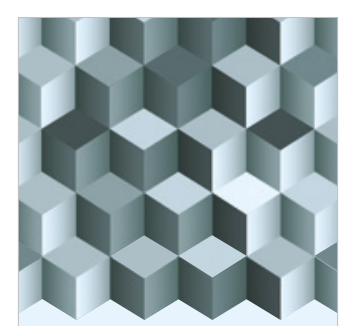

Journal of

Function Spaces
The Scientific

World Journal

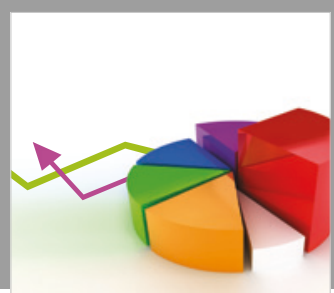

Journal of

Probability and Statistics
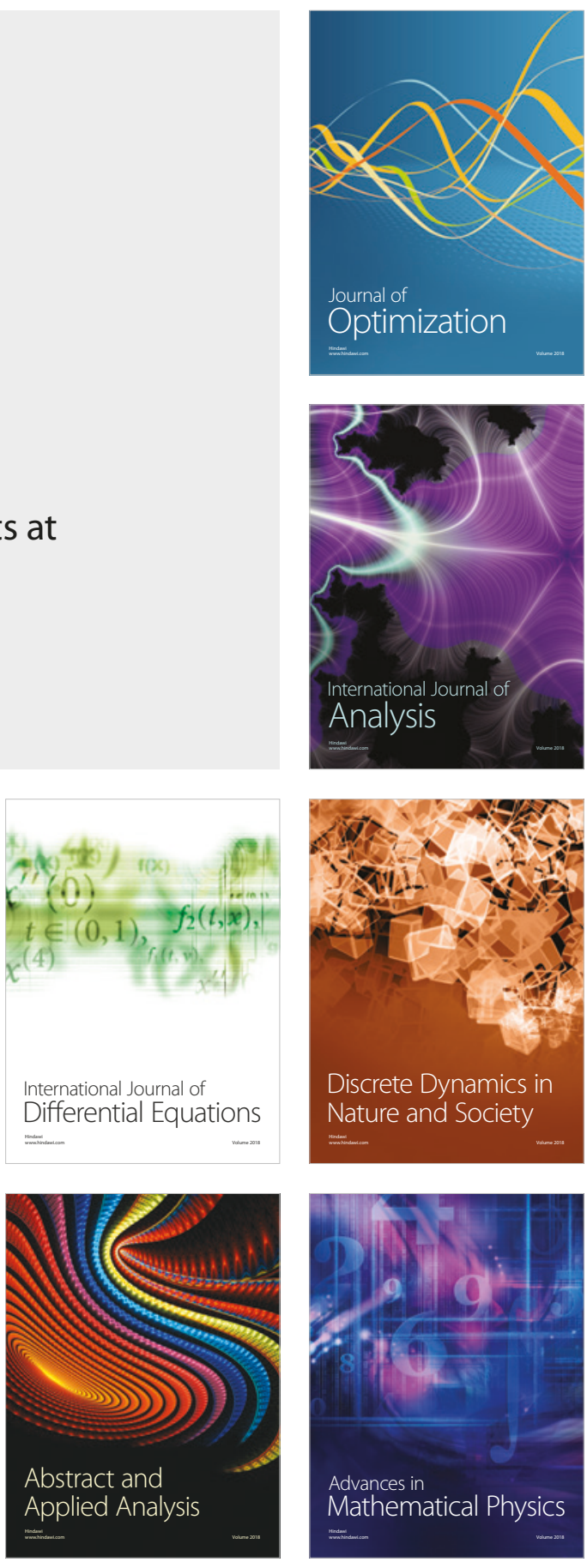